\title{
Os quirópteros do Novo Mundo a América e o morcego hematófago no relato de viajantes quinhentistas*
}

\author{
The bats of the New World \\ America and the blood-eating bat according \\ to the cinquecentist travelers
}

\begin{abstract}
Christian fausto moraes dos santos Doutor/COC Fiocruz - RJ ; Pós-Doutorando/UFMG, Universidade Estadual de Maringá/DHI/Laboratório de Arqueologia, Etnologia e Etno-História. Av. Colombo, 5790 - Maringá-PR. chfausto@ hotmail.com

VITOR DE SOUZA FERREIRA Mestre/UEM

Universidade do Centro Oeste Rua Presidente Zacarias, 875 - Guarapuava-PR. vs.ferreira@ig.com.br

LÍGIA CARREIRA Doutora/EERP- USP Universidade Estadual de Maringá/DEN Av. Colombo, 5790 - Maringá-PR ligiacarreira@ hotmail.com
\end{abstract}

RESUMO A chegada do europeu ao Novo Mundo irá revelar não somente o contato com novas etnias ou fontes de renda; uma biota completamente desconhecida se revelará nos relatos de praticamente todos os viajantes que se aventuraram na América quinhentista. Neste contexto, um mamífero

Artigo recebido em 02/06/2006. Aprovado em 12/12/2006.

(Os autores agradecem a Shirley S. Pereira da Silva pelo fornecimento de material bibliográfico o qual contribuiu para elaboração deste artigo). 
em especial será objeto de vários relatos: o morcego hematófago. Tomando como base as informações contidas nos relatos e descrições de viajantes, colonizadores e evangelizadores do Velho Mundo que se aventuraram na América do séc. XVI, pretendemos analisar não somente algumas questões pertinentes a História da nomenclatura, morfologia e etologia dos morcegos americanos, mas também traçarmos um estudo histórico sanitário desta espécie, hoje conhecida como um dos maiores vetores do vírus rábico.

Palavras-chave América, século XVI, morcego hematófago

ABSTRACT The arrival of the Europeans in the New World will reveal not only the contact with new cultures or new riches; a completely unknown species will be revealed in the reports of practically all the travelers that came to America. In this context, a mammal will be the object of various reports; the blood-eating bat. Based upon information contained in the reports and descriptions of the travelers, colonizers and missionaries from the Old World that ventured into XVI century America, we intend to analyze not only issues related to the history of the naming, morphology and etiology of the American bat but we will also trace a historical sanitary study of this species known today as one of the biggest retainers of the hydrophobia virus.

Key words America, XVI century, vampire bat

De acordo com K. F. Koopman, ${ }^{1}$ existem no Brasil cerca de 126 espécies de morcegos. Delas, apenas as do gênero Desmondus são hematófagas, ou seja, alimentam-se de sangue. Porém, o fato de se alimentar de sangue faz com que esta espécie de morcego seja vista como um ser daninho, nocivo ao homem. Até meados do século XX, a idéia de extirpar essa espécie de quiróptero, como única solução para os problemas causados à saúde humana e às criações, ainda era freqüente. O próprio von Ihering ao falar dos morcegos do Brasil coloca que:

Do ponto de vista utilitário é difícil afirmar, como conclusão final, se os morcegos nos são úteis ou nocivos, pois que se trata de um conjunto muito heterogêneo. É certo que muitas espécies são úteis, porque dão caça a inúmeros insetos; mas outras danificam as frutas do pomar e a espécie hematófaga (Desmondus rufus) causa sério prejuízo à criação. ${ }^{2}$

1 KOOPMAN, K. F. Order Chiroptera. In: WILSON, D. E. and REEDER, D. M. (eds.) Mammal species of the world, a taxonomic and geographic reference. $2^{\mathrm{a}}$.ed. WASHINGTON D.C.: Smithsonian Inst., 1993, p.137-241.

2 IHERING, Rodolpho von. Dicionário dos animais do Brasil. São Paulo: Ed.UNB, 1968, p.464. 
Assim concebia-se a presença do morcego na natureza. Seria ele, afinal, útil, inútil, benéfico ou nocivo? Esse questionamento sempre acompanhou as espécies que de algum modo interferem na sobrevivência humana. Alfred Crosby $^{3}$ afirmou que o termo erva daninha nada mais é que uma planta "no lugar errado", ou seja, uma espécie vegetal que floresce em meio a uma cultura agronômica humana. Parafraseando Crosby, em relação aos morcegos hematófagos, quem estaria "no lugar errado" é a espécie humana. Foi o homem europeu que, após a chegada à América, ao interferir no ambiente, criou condições para que este animal, que antes se alimentava de animais silvestres e mais raramente de indígenas, passasse a atacar, cada vez com maior freqüência, as criações de animais domésticos por ele introduzidos, o que teve como conseqüência também o aumento do seu contato com os humanos.

Não necessitamos aqui citar ostensivamente os inúmeros mitos que se criaram a partir desse quiróptero. Na lei mosaica, o morcego era um animal impuro, que se tornou símbolo de idolatria e pavor. Já entre os índios tupisguarani, o morcego (embora em uma semiologia diferente) também está associado ao terror. Para os tupinambás, o fim do mundo será precedido pela desaparição do sol, que será devorado por um morcego. ${ }^{4} \mathrm{Na}$ tradição dos alquimistas, o morcego é entendido como um ser híbrido, ou seja, uma mistura de rato e pássaro. Por esta ambivalência, o morcego representaria o andrógino, o dragão alado e os demônios. Suas asas seriam as mesmas que compõem o corpo dos habitantes do inferno. Tais interpretações podem ser reificadas em uma rica iconografia acerca das figuras demoníacas na História do ocidente. Afinal, qual demônio não possui em suas costas asas que lembram a de um morcego? ${ }^{5} \mathrm{O}$ Conde de Buffon no século XVIII chega mesmo a chamá-lo de um ente-monstro.

Os hábitos alimentares dos morcegos hematófagos deram origem a inúmeros mitos e associações simbólicas. Exemplo bastante conhecido é o dos vampiros da Transilvânia, como se naquela antiga província do leste europeu existisse esta classe de quiróptero. Cabe aqui lembrar que os morcegos hematófagos têm sua distribuição biogeográfica limitada às Américas do Sul e Central, não existindo nenhum similar europeu. A associação simbólica do Desmondus com o famoso conde Drácula (que combateu ferozmente os "pagãos" muçulmanos na Idade Média) ocorreu porque dizia-se que este último tinha o hábito de empalar e beber o sangue de seus inimigos adoradores de Alá. Essa associação só pôde ser efetivada após a chegada do europeu ao Novo Mundo, pois, até o século XVI, des-

3 CROSBY, Alfred. O imperialismo ecológico: a expansão biológica da Europa, 900-1900. São Paulo: Companhia das Letras, 1993.

4 CHEVALIER, Jean e GHEERBRANT, Alain. Dicionário de simbolos. São Paulo: José Olympio Editora, 1996.

5 A obra de KAPPLER, Claude. Monstros, demônios e encantamentos no fim da Idade Média, possui ampla iconografia acerca de criaturas diabólicas portadoras de "asas de morcego". 
conhecia-se na Europa a existência de tal espécie de quiróptero. ${ }^{6}$ Porém o morcego, mesmo o pertencente à classe dos frugívoros e/ou insetívoros, já era, mesmo antes do século XVI, um símbolo de mau agouro na Europa.

Como teria sido então a reação dos primeiros viajantes europeus ao se depararem no Novo Mundo com uma família de quirópteros que tinham como fator agravante do temor que despertavam sua alimentação a base de sangue? Gonzales Fernándes de Oviedo, em seu Sumário de La Natural Historia de Las Índias, escrito a partir de suas observações acerca da geografia, animais e plantas das Índias Ocidentais (o que corresponde à América Central), em 1514, classifica os murciélagos como pássaros noturnos.

Para Oviedo, tal classificação se explica porque os morcegos, ao saírem à noite para se alimentarem, disputam um espaço que por direito pertence às aves: os céus. Por essa época, era comum que as classificações de elementos da natureza, como no caso dos animais, se fizessem a partir de sua relação com o ambiente em que vivem. Ao que parece, Oviedo, mesmo classificando os morcegos como pássaros noturnos, entende que estes por voarem estão exercendo uma qualidade que parece não ser sua por direito. Desta maneira, para fundamentar seu raciocínio acerca da capacidade de voar deste mamífero Oviedo descreve que:

En Tierra-Firme hay unas aves que los cristianos llaman pájaros nocturnos, que salen al tiempo que el sol se pone, cuando salen los murciélagos, y es grande la enemistad de estas aves com los dichos murciélagos; y luego andan volándolos y persiguiendo a los dichos murciélagos, golpeándolos; lo cual no se puede ver sin mucho placer de quien los mira. ${ }^{7}$

Descrevendo tal contenda, Oviedo parece querer justificar sua impressão de que o morcego é um estranho no mundo das aves, ou seja, os céus. Sua presença ali é a de um penetra. Haja visto que os pássaros noturnos no México, segundo José Miranda (revisor contemporâneo da obra de Oviedo), são chamados tapacaminos, sendo estes insetívoros e não territorialistas. Conhecer aquilo que pertence a uma espécie propriamente ou a um espécime é o meio pelo qual construímos a identidade, e aquilo que a marca é definido pelo resíduo das diferenças.

Para Oviedo o morcego deveria ser classificado como um pássaro noturno por voar à noite assim como as aves noturnas, mas havia algo de destoante no morcego, pois eles "tienen aquella manera de alas". ${ }^{8}$ Oviedo não será o único a classificar o morcego com tal nomenclatura, o português Gabriel Soares de Souza, senhor de engenho e roças nas terras do Brasil,

6 McNALLY, Raymond P. e FLORESCU, Radu. Em busca de Drácula e outros vampiros. São Paulo: Mercuryo Ed., 1995.

7 OVIEDO, Gonzalo Fernández de. Sumario de la natural historia de las Índias. (1514) México: Fondo de Cultura Economica, 1996, p.171. (grifo meu)

8 OVIEDO, Gonzalo Fernández de. Sumario de la natural historia de las Índias, p.171. 
ao compor o seu Tratado Descritivo do Brasil em 1587, inscreve o morcego na sua classe denominada, "em que se contém a natureza de algumas aves noturnas". 9

No século XVI, os teóricos do mundo natural irão buscar a identidade dos seres vivos na marca positiva que os mesmos pudessem ter. Qualquer diferença que existisse entre as aves não seria estabelecida a partir das diferenças morfológicas que poderia existir entre elas, como o formato do bico, da perna, etc, mas sim na maneira elas se relacionam com o ambiente em que vivem. Assim, mais geralmente as aves são classificadas como: 1) as que vivem sobre a água; 2) as que caçam à noite; 3) as que se alimentam de carne podre. ${ }^{10}$ Por isso, tanto Oviedo, como Gabriel Soares de Souza classificam o morcego como ave noturna. Mas, para Oviedo, a aparência tornava tal classificação desconcertante. Entretanto, o morcego estava lá, voando em meio aos pássaros. Deste modo a única maneira de se prosseguir em uma classificação mais apurada dependia do aval dos próprios pássaros. Ou seja, o estranhamento etológico entre aves noturnas e morcegos e a perseguição que estes últimos sofriam no céu construído por Oviedo foram maneiras encontradas pelo mesmo para demonstrar a existência de diferenças entre as aves noturnas e os morcegos, posto que estes não são aves autênticas, pois, nesse caso, não seriam perseguidos em pleno vôo.

Este inconformismo taxonômico de Oviedo fica mais claro no capítulo XXXV de seu Sumário, quando ele trata exclusivamente dos Murciélagos:

Pues en el capítulo de suso escrito se dijo de la contención de los pájaros nocturnos y murciélagos, quiero concluir com los dichos murciélagos. E digo que en Tierra-Firme hay mucho de ellos, que fueron muy peligrosos a los cristianos. ${ }^{11}$

Pode-se considerar que, para o homem do século XVI, as espécies perigosas de morcego certamente eram as hematófagas. Os morcegos hematófagos encontrados no Brasil são de três espécies diferentes: Diaemus youngii (Jentink), Diphylla ecaudata (Spix, 1823) e Desmodus rotundus (Geoffroy, 1810). ${ }^{12}$ Esta última pode ser considerada a mais importante por alimentar-se preferencialmente do sangue de mamíferos e por ser a espécie mais freqüente. As outras duas, ao contrário, alimentam-se preferencialmente do sangue de aves e são menos freqüentes. Portanto, é provável que as narrativas de Oviedo sobre o morcego vampiro sejam referentes a D. rotundus. Ele considera perigosa a espécie que observa na medida em que,

9 SOUZA, Gabriel Soares de. Tratado descritivo do Brasil em 1587. São Paulo: Brasiliana, 1971, p.235.

10 BELON, Pierre. Histoire de nature des oiseaux. Paris, 1555. (microfilme)

11 OVIEDO, Gonzalo Fernández de. Sumario de la natural historia de las Índias, p.171.

12 Obs: Os nomes e as datas entre parênteses não são referências bibliográficas. Trata-se do nome do zoólogo que, pela primeira vez, descreveu a espécie e o ano em que ocorreu. 
alguns cristianos murieron entonces, y otros estuvieron en peligro de morir, hasta que de los indios se supo la manera de cómo se había de curar el que fuese picado de ellos. (...), y acostumbram picar de noche, y comúnmente por la mayor parte pican del pico de la nariz, o de las yemas de las cabezas de los dedos de las manos o de los pies, y sacan tanta sangre de mordedura, que es cosa para no se poder creer sin verlo. ${ }^{13}$

Enquanto portador de patologias e perigoso para o homem, Oviedo afirma que alguns cristãos morreram "picados", ou seja, mordidos por morcegos e outros quase morreram. Curioso notar que José Miranda inclui uma nota no Sumario, de Oviedo, onde afirma que os morcegos descritos pelo autor são vampiros. Miranda tem razão ao classificá-los como hematófagos, mas vai um pouco além e diz que a saliva do morcego, por ser anticoagulante, impede a cicatrização. Por essa razão, segundo Miranda, quando não se trata a ferida causada pela mordida a tempo, a perda de sangue pode provocar a morte ou mesmo deixar seqüelas graves no organismo. Que a saliva dos morcegos hematófagos é altamente anticoagulante é informação verossímil. De acordo com A. M. Greenhall, ${ }^{14}$ isso ocorre graças a um potente ativador denominado desmoquinase, responsável por ativar o sistema fibrolítico de mamíferos. Mas afirmar que isto pode causar a morte de um ser humano é uma afirmação sem fundamento, pois a incisão causada pela mordida do morcego é uma abertura arredondada de aproximadamente $5 \mathrm{~mm}$ de diâmetro e $4 \mathrm{~mm}$ de profundidade. ${ }^{15}$ Mesmo que o sangue não coagulasse, não verteria em quantidade suficiente para causar o desenvolvimento de uma anemia ou até uma situação hemorrágica grave que pudesse levar a morte de um ser humano. Além disso, o efeito anticoagulante cessa algumas horas após o término da alimentação do morcego, a qual dura 25 minutos em média.

O que podemos mais facilmente concluir é que as vítimas fatais do morcego hematófago, descritas por Oviedo nas Índias Ocidentais, ou sofreram infecções secundárias devido à falta de assepsia do local da mordida ou contraíram raiva. Nesse último caso, seriam as primeiras vítimas de raiva que se tem notícia no Novo Mundo, pois sabe-se que o vírus rábico é eliminado juntamente com a saliva de mamíferos infectados (no caso os morcegos), o qual penetra no organismo através de soluções de continuidade (lesão do tecido) produzidas por mordeduras. A doença pode apresentar um período de incubação que varia conforme alguns fatores: o local onde o vírus penetra; a proximidade entre os troncos nervosos e a ferida; a quantidade do vírus inoculado e a procedência do vírus em relação à espécie animal que aflige a mordedura. Assim o período de incubação mais freqüente é de dois

13 OVIEDO, Gonzalo Fernández de. Sumario de la natural historia de las Índias, p.171.

14 GREENHALL, A. M. Identification of the vampire bat. World Animal Review, FAO, n.2, p.44-48, 1972.

15 GREENHALL, A. M. Identification of the vampire bat, p.44-48. 
a três meses, porém estes podem variar entre um período mínimo de seis dias chegando a se estender por até um ano ou mais. Os cristãos mortos pelos "ataques" dos morcegos então descritos por Oviedo podem ter sido vítimas da visita de espécimes vetores do vírus rábico altamente infectados, que, como agravante, morderam em locais com grande concentração de troncos nervosos, como a mão, ou muito próximos do sistema nervoso central, como as orelhas e o nariz, o que teria acelerado consideravelmente o processo de incubação do vírus.

Mas, Oviedo não se limita a descrever o ataque dos morcegos hematófagos. Ele procura tomar nota daquilo que, segundo os indígenas mexicanos do século XVI, seria um antídoto contra a mordedura dos mesmos, "porque, por no saberse entonces el fácil y seguro remedio que hay contra la mordedura del murciélago, alguns cristianos murieron". ${ }^{16}$ Nesse ponto, Oviedo alerta para os inconvenientes de se ignorar o saber do outro, no caso o autóctone americano. Prossegue essa parte descrevendo os procedimentos adotados e ensinados pelos índios:

El remédio de esta mordedura es tomar un poco de rescoldo de la brasa, cuanto se pueda sufrir, y ponerlo en el bocado. Hay asimismo outro remedio, y es tomar agua caliente, y cuanto se pueda sufrir la calor de ella, lavar la mordedura, y luego cesa la sangre y el peligro, y se cura muy presto la llaga de la picadura, la cual es pequeña, y saca el murciélago un bocadico redondo de la carne. A mí me han mordido, y me he curado con el água de manera que he dicho. ${ }^{17}$

No método explicado pelos indígenas a Oviedo, percebe-se que houve a cauterização dos ferimentos deixados pelo morcego através da brasa em fogo, impedindo assim as infecções secundárias. Outro método que ele descreve como indicado consiste em que se pegue água o mais quente possível e se lave com ela o local da ferida. A lavagem da ferida é um procedimento até hoje empregado em mordedura de animais, tanto para evitar infecções secundárias, como para diminuir a quantidade de vírus inoculado. A preferência pela água quente se explica pelo fato de que a pessoa irá transpirar em seguida. No século XVI, acreditava-se que a prática de se purgar para fora do corpo excrementos ou secreções, por meio da sudorese e/ou de sangria, fazia com que o veneno e o mal que ele contém fossem expurgados. Nesse período, a medicina Galênica em vigor, baseada na teoria dos humores, tinha ampla aceitação. Porém, a questão permanece: se não há possibilidade de se morrer de hemorragia ou infecções secundárias pela mordida do morcego, teriam realmente perecido de raiva os companheiros de Oviedo? Talvez.

16 OVIEDO, Gonzalo Fernández de. Sumario de la natural historia de las Índias, p.172.

17 OVIEDO, Gonzalo Fernández de. Sumario de la natural historia de las Índias. 
Observa-se ainda, no texto de Oviedo, um dado importante da etologia dos morcegos hematófagos:

Tienen outra propriedad, y es, que si entre cien personas pican a un hombre una noche, después la siguiente o outra no pica el murciélago sino al mismo que ya hubo picado, aunque esté entre nuchos hombres. ${ }^{18}$

Confirmado cientificamente somente séculos mais tarde, esta característica comportamental dos morcegos hematófagos de visitarem noite após noite sempre a mesma vítima foi constatada desde o século XVI, como se observa pelo relato de Oviedo. No Brasil quinhentista, outras observações importantes serão feitas acerca da etologia deste quiróptero com relação a sua prole e seu habitat, uma vez que o português Gabriel Soares de Souza descreve que:

Aos morcegos chamam os índios andura, (...) criam nos recôncavos das árvores, e nas casas e lugares escuros; as fêmeas parem quatro filhos e trazem-nos pendurados ao pescoço com as cabeças para baixo, e pegados com as unhas ao pescoço da mãe. ${ }^{19}$

É certo que os viajantes da América quinhentista em muito antecederam o sueco criador da sistemática zoológica e botânica Carl von Linné, porém, como podemos observar, suas descrições acerca da fauna e flora do Novo Mundo estão longe de serem meros relatos literários ou fantasiosos. Quanto a Oviedo, este termina o relato sobre os murciélagos descrevendo o tamanho dos mesmos e, curiosamente, contando como eram escaldados em água quente para serem comidos:

quedan de la manera de los pajaritos de cañuela, y muy blancos y muy gordos y de buen sabor, según dicen los índios, y aun algunos cristianos, que los comen también, en especial aquellos que son amigos de probar lo que vem hacer a otros..$^{20}$

As descrições do morcego hematófago pelos europeus no século XVI é exemplo da forma como se caracterizavam os relatos sobre o mundo natural americano àquela época. Não bastava somente descrever a espécie, o formato de suas pernas e das patas, seu alimento, seu habitat, etc. Para dar a conhecer um animal ou uma planta era necessário também contar o que os antigos diziam sobre ele, que tipo de iguarias podiam ser feitas a partir de suas asas e mesmo relatar alguns casos interessantes que mostravam tanto o mal que podiam causar, quanto o bem. Isso foi o que sucedeu com um morcego com que se deparou o sapateiro e viajante

18 OVIEDO, Gonzalo Fernández de. Sumario de la natural historia de las Índias.

19 SOUZA, Gabriel Soares de. Tratado Descritivo do Brasil em 1587, p.234.

20 OVIEDO, Gonzalo Fernández de. Sumario de la natural historia de las Índias, p.173. 
francês Jean de Léry, nos momentos iniciais da conquista da terra de Santa Cruz. Em seu livro, ele relata como um morcego cirurgião salvou a vida do criado de um padre:

Achava-se doente em Santa Fé de Caribici, vítima de uma pleuris, o criado de um frade. Como não encontrassem a veia para sangrá-lo foi deixado por morto; mas à noite apareceu um morcego que o mordeu no calcanhar descoberto, fartando-se de sangue; e como deixasse a veia aberta, tanto sangue perdeu a vítima, que sarou. Foi o morcego, digo-o eu como historiador, o benemérito cirurgião do pobre doente..$^{21}$

Como já afirmado, a prática da sangria era uma realidade clínica na medicina da época tanto na França, quanto no Brasil, onde perdurará até o fim do Império. A idéia subjacente à defesa da sangria como método curativo era a de que o sangue doente, assim como as excreções e secreções, ao esvair-se do corpo, daria lugar no organismo do enfermo a uma nova leva de sangue, desta vez saudável. A sangria era feita utilizando os bisturis-navalhas ou mesmo as sanguessugas. A sangria era panacéia bem aceita e todo e qualquer cirurgião estava habilitado a realizar tal intervenção, não nos esquecendo que o cirurgião podia ser também barbeiro. ${ }^{22} \mathrm{~A}$ partir dessa perspectiva podemos entender como a visita vampiresca feita por nosso "pequeno cirurgião de emergência" causou tão boa impressão no francês Jean de Léry.

O fato de Léry creditar a esse morcego a cura do doente faz com que, por analogia, ele tenha uma boa impressão dos morcegos no Brasil. Assim termina o caso afirmando que,

não obstante o mal que fazem os morcegos da América, longe estão de ser nocivos como essas aves sinistras a que os gregos chamavam estrígias e que, segundo Ovídio, sugavam meninos no berço, razão pela qual esse nome foi dado mais tarde às feiticeiras. ${ }^{23}$

Para Léry, o morcego hematófago brasileiro poderia, em alguns casos, ser considerado um sarjador da natureza, um agente de saúde. Como era comum, Jean de Léry não se preocupa somente em descrever a espécie em si, mas também se preocupa em relatar histórias sobre ela e inclusive tendo como referência a mitológicas grega sobre as estrígias. ${ }^{24}$

21 LÉRY, Jean de. Viagem a terra do Brasil (1578). Rio de Janeiro: Biblioteca do Exército Editora, 1961, p.108.

22 Com referência aos cirurgiões-barbeiros poderemos encontrar referências sobre eles em tratados médicos do século XVIII como em FURTADO, Júnia F. (org.) Erário Mineral de Luís Gomes Ferreira. Belo Horizonte: Fundação João Pinheiro, 2002. (Coleção Mineiriana); ou nos relatos de viajantes ingleses do século XIX, como no caso de John Mawe (1764-1829), MAWE, John. Viagens ao interior do Brasil. Belo Horizonte: Editora Itatiaia,1978.

23 LÉRY, Jean de. Viagem a terra do Brasil, p.108.

24 Do Latin strigae, sing. Striga, "a que pia como uma coruja". Na crença popular romana, demônios passeriformes que roubavam crianças, para sugar seu sangue, e utiliza-las como oferendas. Às vezes dizia-se serem mulheres 
A tripartição entre observação, descrição e mito são procedimentos hoje considerados normais pelos cientistas contemporâneos, mas eram elementos indissociáveis quando se tratava dos viajantes preocupados em descrever a natureza do Novo Mundo no século XVI. Tudo que o morcego lembrasse, fosse uma história, uma refeição, uma cura, uma doença, ou até um outro animal, acompanharia a descrição. Isso tornaria o animal ou planta mais visível ao leitor europeu, pois esses relatos nem sempre eram acompanhados de imagens. Mesmo quando uma representação pictórica acompanhava a descrição, na maioria das vezes, essa era feita na Europa por terceiros. Com o intuito de descrever morfologicamente o morcego, por exemplo, Léry diz que "no país existem morcegos do tamanho das nossas pequenas gralhas". ${ }^{25}$

Quanto à morfologia, a analogia será mecanismo imprescindível para se proceder à descrição. Gabriel Soares de Souza, ao descrever o andura (nome dado pelos indígenas ao morcego), afirma que "há alguns muito grandes, que tem tamanhos dentes como gatos, com que mordem". ${ }^{26}$ Para o alemão Hans Staden, os arcabuzeiros, um tipo de morcego, possuem dentes de gato, corpo de gralhas e são "maiores do que aqui na Alemanha". ${ }^{27}$ Os morcegos, como os demais animais e plantas, vão sendo "montados" morfologicamente para que se possa explicar ao leitor sua aparência. A utilização do "conhecido em pedaços" para explicar o desconhecido por inteiro será prática marcantemente utilizada por aqueles que chegam ao Novo Mundo, com o intuito de descrever o que vêem aos que permaneceram na Europa. ${ }^{28}$

Nas relações entre o Velho e o Novo Mundo, a necessidade do reconhecimento engendra operações simbólicas e significações culturais que permitiram um alargamento do universo. A constatação de que se está diante de algo distinto sugere indagações. Isso certamente leva a novas metodologias de classificação, nascidas de questionamentos simples, como por exemplo: "esta espécie é diferente?". As diferenças não serão possíveis de serem assinaladas sem o método comparativo. Esse é o teor das narrativas sobre o Novo Mundo de cronistas e conquistadores do século XVI. Não há como negar que, ao chegarem nos trópicos, esses homens se deparam com o inusitado: são seres e circunstâncias improváveis dentro de um novo contexto geográfico.

Quando à questão sanitária, todos os viajantes que descreveram o morcego hematófago na América quinhentista reclamam das visitas notur-

velhas que se haviam transformado em pássaros. LURKER, Manfred. Dicionário dos deuses e demônios. São Paulo: Martins Fontes, 1993, p.68.

25 LÉRY, Jean de. Viagem a terra do Brasil, p.108.

26 LÉRY, Jean de. Viagem a terra do Brasil.

27 STADEN, Hans. Duas viagens ao Brasil. (1576) Belo Horizonte/São Paulo: Ed. Itatiaia/EDUSP, 1974, p.163.

28 FOUCAULT, Michel. As palavras e as coisas. São Paulo: Martins Fontes, 1991. 
nas às cabanas e às camas, onde o mesmo se fartava de dedos dos pés e das mãos, testas, orelhas e narizes. Porém, apesar de especularmos a partir do relato de Oviedo da possibilidade do morcego descrito por ele ter contaminado alguns de seus companheiros com o vírus rábico, não encontraremos nada semelhante nos viajantes da América Portuguesa. Todos relatam a ação vampiresca do morcego, mas não há, ao que parece, referência a vítimas fatais. Jean de Léry chega a afirmar que os indígenas encaravam tais visitas noturnas com naturalidade, e ele, quando atacado, contou que "durante dois ou três dias senti dificuldade em calçar-me por ter ofendida a extremidade do dedão, embora não fosse grande a dor". ${ }^{29}$ Quando algum viajante se refere às características nocivas do morcego, afirma no máximo que "a sua mordedura é mui peçonhenta" ${ }^{30} \mathrm{~A}$ partir do relato de Léry parece que o incomodo causado pelos morcegos é mínimo, apesar dos hematófagos serem transmissores da raiva em potencial. Essa parece ser também a opinião de Hans Staden, que conta que eles

\begin{abstract}
voam de noite nas cabanas e em torno das redes em que dormem as pessoas. Quando percebem que alguém dorme e não os afugenta, voam-lhe aos pés, mordem e sugam, ou mordem a testa, voando depois em retirada. Quando estava entre os índios, arrancavam-me muitas vezes um pedaço dos artelhos. Quando acordava, via os dedos sangrando. Mordem os selvagens, porém, habitualmente na testa. ${ }^{31}$
\end{abstract}

Contudo, não sabemos como a raiva era diagnosticada na época, ou mesmo se a doença já existia no Brasil. Talvez muitas tenham sido as vítimas infectadas com o vírus rábico nesta época sem o saber. De qualquer forma, estes viajantes não associaram o ataque do morcego aos sintomas da raiva, pois eles próprios foram muitas vezes mordidos sem, contudo, contraírem algum mal. Além da dor, descrevem apenas a sensação desagradável de acordarem com as roupas de cama manchadas de sangue. A associação do morcego com uma doença que poderia se manifestar meses após o contágio era algo improvável.

No entanto, Gabriel Soares de Souza chama a atenção para outros males que o morcego podia causar ao homem. Ele descreve que, "nas casas de purgar açúcar se criam infinidade deles, onde fazem muito dano, sujando o açúcar com o seu feitio, que é como o de ratos". ${ }^{32} \mathrm{O}$ autor se queixa da contaminação do açúcar. Afinal ele era senhor de engenho. É ainda Gabriel Soares de Souza o primeiro a afirmar que alguns morcegos alimentam-se de açúcar, fato relacionado à espécie Glossophaga soricina e

29 LÉRY, Jean de. Viagem a terra do Brasil.

30 SOUZA, Gabriel Soares de. Tratado descritivo do Brasil em 1587, p.234.

31 STADEN, Hans. Duas viagens ao Brasil, p.154.

32 SOUZA, Gabriel Soares de. Tratado descritivo do Brasil em 1587, p.234. 
corroborado pelos nativos em Finca Lonersa, Santa Ana, Costa Rica. ${ }^{33}$ Sua preocupação, porém, poderia não ser simplesmente de ordem econômica, mas também sanitária. Sabe-se hoje que os excrementos de morcegos podem transmitir Histoplasmose, mal este que pode ser adquirido simplesmente inalando os esporos do fungo Histoplasma capsulatum, presentes nos mesmos excrementos. O perigo representado pelos excrementos de morcegos que habitavam o teto dos engenhos não era se referia apenas à cana-de-açúcar, mas também à contaminação do próprio ambiente, ou seja, as próprias instalações do engenho.

No que se refere ao velho maniqueísmo de julgar o morcego como um animal do bem ou do mal, nem mesmo naturalistas renomados do nosso século, como von Ihering, se furtaram a opinar sobre o tema:

Como proteger umas e exterminar as outras espécies? Sem dúvida os lavradores prejudicados devem defender-se e, afinal, o pequeno proveito esperado dos morcegos insetívoros não é de tanta importância como às vezes tem sido apregoado. Havendo muitos morcegos daninhos, é preciso revistar as locas, taperas e outros esconderijos das redondezas e dizimar ou afugentar os bandos. ${ }^{34}$

É certo que hoje, no início do século XXI, esta não seja opinião corrente da maioria dos zoólogos acerca dos quirópteros. Porém em qualquer casa veterinária brasileira poderemos encontrar inúmeras pastas vampiricidas. É verdade ainda que, na atualidade, os maiores agentes causadores da raiva entre os humanos são o morcego (D. rotundus) e o cão (Canis familiaris, Linneus, 1758), e que o morcego é um animal fora do alcance de qualquer estratégia de vacinação preventiva, como ocorre com os cães e gatos. No estado do Paraná, por exemplo, um único caso de raiva humana foi constatado na década de oitenta do século XX, tendo sido causado por um morcego. ${ }^{35}$ Além disso, afirma-se que, hoje, os morcegos hematófagos são, na área rural, responsáveis pela disseminação da raiva bovina. Sem dúvida a existência dos morcegos tem se tornado para algumas instituições um problema.

Mas, devido à falta de informações no campo sobre a identificação correta dos morcegos hematófagos, o processo de extermínio dos morcegos leva a cabo outras inúmeras espécies não hematófagas, que, além de não causarem problemas às criações, executam importante manejo de controle de insetos, polinização e dispersão de sementes.

Por fim, cumpre lembrarmos que, desde a chegada do europeu ao Novo Mundo no século XVI, a biota americana tem sofrido danos irreparáveis.

33 GARDNER, A. L. Feeding Habits. Biology of Bats of the New World Family. In: BAKER, R. J.; JONES JUNIOR, J. K. e CARTER, D. C. Special publications of the Museum Texas Tech University. U.S.A: Lubbock, 1977, p.293-350.

34 IHERING, Rodolpho von. Dicionário dos animais do Brasil. São Paulo: Ed. UNB, 1968, p.464.

35 SECRETARIA DE SAÚDE. Boletim Epidemiológico do Paraná, ano IX, n.68, março/90, 1990. 
Se o morcego hematófago hoje ataca o gado, as galinhas e as ovelhas ou se reproduz ostensivamente é porque, dentre outros motivos, suas presas naturais foram se tornando raras, seus habitats foram depredados, o que promoveu o maior contato dos morcegos hematófagos com os homens e suas criações. A melhor solução torna-se, ao que parece, controlar uma espécie que se tornou consideravelmente nociva, em uma visão antropocêntrica, graças em grande parte a ação do próprio ser humano. 